\title{
The effects of para-hydroxybenzoic acid treatment on photosynthetic parameters of Populus $\times$ euramericana "Neva"
}

\author{
G.T. LIANG ${ }^{*}$, S.Y. ZHANG ${ }^{*}$, J. GUO*, R. YANG*, H. LI* ${ }^{*}$, X.C. FANG ${ }^{*}$, and G.C. ZHANG ${ }^{*++}$ \\ Shandong Province Key Laboratory of Soil Erosion and Ecological Restoration, Key Laboratory of Agricultural Ecology \\ and Environment, College of Forestry, Shandong Agricultural University, Taian 271018, China* \\ College of Life Science, Linyi University, Linyi 276000, China**
}

\begin{abstract}
As a common tree species in northern China, Populus $\times$ euramericana "Neva" has an important practical value for the study of continuous cropping obstacles in poplar cultivation. Plant allelopathy is the main reason for continuous cropping obstacles, which are caused by allelochemicals, such as para-hydroxybenzoic acid (p-HB). The objective of this study was to investigate the effects of $\mathrm{p}-\mathrm{HB}$ on the photosynthesis of poplar. Photosynthetic parameters of Populus $\times$ euramericana "Neva" poplar were determined in a pot culture experiment where five p-HB concentrations were used $(0,1,2,4$, and $6 \mathrm{mmol} \mathrm{L}^{-1}$ ). Each seedling was treated with $4 \mathrm{~L}$ of p-HB solution every seven days, ten times in total. $\mathrm{p}$-HB inhibited the photosynthesis of poplar significantly, as shown by a clear decline in the net photosynthetic rate. Our results indicated nonstomatal limitation responsible for the photosynthesis reduction.
\end{abstract}

Additional key words: chlorophyll fluorescence; cropping obstacle; gas exchange; plant allelopathy; poplar.

\section{Introduction}

Plant allelopathy was initially proposed in 1937 and since then it has been addressing more and more concerns in the academic community (Makoi and Ndakidemi 2007). In the practice and research of agricultural production, it has been found that many crops, which suffer from continuous cropping obstacles, release allelochemicals resulting in an autotoxic effect. So far, most of the discovered allelochemicals are secondary metabolic substances, of which low molecular-mass organic acids, phenolic compounds, and terpenoids are the most common compounds (Rice 1984, Li et al. 2002). Patrick (1971) found that phenolic acids have stronger allelopathic activity and strong toxicity to trees (Kuiters and Sarink 1986) and can cause soil ecological environment changes, resulting in a decline in soil fertility. Indeed, phenolic acids are considered to be an important cause of the continuous decline of cropping soil fertility in plantations (Weidenhamer and Romeo 2004).
Photosynthesis is essential for plant survival, growth, and production (Chen et al. 2013). Studies of the relationship between photosynthesis and physiological processes involving different phenolic acids at various concentrations could provide in-depth understanding of plant allelopathy, encourage a deeper understanding of the adaptive capacity of different plants in continuous cropping environments, and provide physiological evidence for research on the mechanism underlying continuous cropping obstacles.

Poplar is one of the most important, fast-growing tree species in the world, an important source of paper-making raw materials with a wide distribution and a high economic value (Wang 1995, Zhao et al.1995). Continuous cropping is one of the most common production modes for poplars, often leading to serious declines in soil fertility and productivity, occasionally resulting in "plant deserts".

Received 18 March 2016, accepted 27 October 2016, published as online-first 13 March 2017.

${ }^{+}$Corresponding author; fax:+865388249169, e-mail: zhgc@sdau.edu.cn

Abbreviations: AQY - apparent quantum yield; $C_{\mathrm{a}}-$ air $\mathrm{CO}_{2}$ concentration; $C_{\mathrm{i}}-$ intercellular $\mathrm{CO}_{2}$ concentration; Chl - chlorophyll; $E$ - transpiration rate; $\mathrm{F}_{0}$ - minimal fluorescence yield of the dark-adapted state; $\mathrm{F}_{0}{ }^{\prime}$ - minimal fluorescence yield of the light-adapted state; $F_{m}$ - maximal fluorescence yield of the dark-adapted state; $F_{m}$ - maximal fluorescence yield of the light-adapted state; $F_{s}-$ steadystate fluorescence yield; $\mathrm{F}_{\mathrm{v}}-$ variable fluorescence; $\mathrm{F}_{\mathrm{v}} / \mathrm{F}_{\mathrm{m}}-$ maximal quantum yield of PSII photochemistry; $g_{\mathrm{s}}-$ stomatal conductance; LCP - light-compensation point; $\mathrm{L}_{\mathrm{s}}$ - stomatal limitation; LSP - light-saturation point; NPQ - nonphotochemical quenching; p-HB - para-hydroxybenzoic acid; $P_{\mathrm{N}}-$ net photosynthetic rate; $P_{\mathrm{Nmax}}-$ light-saturated net photosynthetic rate; $\mathrm{qP}_{\mathrm{P}}-$ photochemical quenching coefficient; $R_{\mathrm{D}}$ - respiration rate; WUE - water-use efficiency; $\Phi_{\mathrm{PSII}}$ - effective quantum yield of PSII photochemistry. 
The rhizosphere soil of different continuous cropping black poplar plantation were analyzed with high performance liquid chromatography (HPLC), indicating that allelochemicals had accumulated in the rhizosphere soil. The $\mathrm{p}-\mathrm{HB}$ content in the second generation of a poplar forest rhizosphere soil increased by $245.5 \%$ from the first generation, while the content of both cinnamic acid and benzoic acid increased by $64.2 \%$ (Tan et al. 2008). Thus, $\mathrm{p}-\mathrm{HB}$ is the main phenolic allelochemical produced by continuous cropping of poplars. Benzoic acid and cinnamic acid inhibited the growth of watermelon radicles, characterized by shorter lengths, browning root caps, less root hairs, and underdeveloped lateral roots (Sun et al. 2006). Phenolic allelochemicals, such as vanillic acid, coumaric acid, caffeic acid, and clove phenol acid also inhibited the growth of bean axial roots and lateral roots (Vaughan and Ord 1990). In addition, cinnamic acid,

\section{Materials and methods}

Materials and treatments: In March 2015, one-year-old healthy branches of $P$. × euramericana "Neva", planted at the forestry ecostation of Shandong Agricultural University (Tai'an, Shadong, China), were cut from the middle and lower part of the crown. The branches were cut to a length of about $20 \mathrm{~cm}$ and a diameter of about $2 \mathrm{~cm}$ and were then inserted into a plastic container. Under field conditions, the cuttings were further grown under hydroponic conditions until roots appeared. In early April 2015, when roots appeared, the cuttings were transferred to an earthen basin with quartz sand as a cultivation matrix. Then, the cuttings were grown under natural conditions with regular watering.

Starting from middle of June, the poplar plants were treated with different concentrations of $\mathrm{p}-\mathrm{HB}$. Plants with similar growth status were selected and divided into five groups, with each group containing 24 seedlings. The groups were treated with $4 \mathrm{~L}$ of p-HB solutions (mixed with $0.2 \%$ ethanol solution; the original liquid concentration was $10 \mathrm{mmol} \mathrm{L}^{-1}$ ) of different final concentrations $\left(1,2,4\right.$, and $\left.6 \mathrm{mmol} \mathrm{L}^{-1}\right)$ with zero concentration as a control every seven days for ten weeks. In late August, three typical experimental plants from each group were selected as the test plants and were then divided in three groups with each group containing five plants. The photosynthetic gas exchange and chlorophyll (Chl) fluorescence parameters of the leaves were measured. Each group was measured daily (repeated three times) and all measurements were completed in three days.

Photosynthetic gas-exchange parameters: A portable photosynthesis system (CIRAS-2, Amesbury, MA, USA) was used to measure photosynthetic light-response parameters. During the measurements, the $\mathrm{CO}_{2}$ concentration of the leaf chamber was maintained at $365 \pm 5 \mu \mathrm{mol} \mathrm{m}{ }^{-2}$, the air temperature was maintained at $26 \pm 1.5^{\circ} \mathrm{C}$, and the relative humidity was maintained at $60 \pm 4.0 \%$. For benzoic acid, and para-hydroxybenzoic acid affected the length of the radicle and plumule of the Chinese fir seeding (Wang et al. 2002). However, only a few studies on the relationship between $\mathrm{p}-\mathrm{HB}$ and poplar photosynthesis have been reported.

P. $\times$ euramericana "Neva" is one of the most common poplar species in northern China, and its wide distribution and rich resources make it an important protection and commercial forest tree species in the plains and deserts of northern China. In addition, the Euramerican poplar has an important practical value for the study of poplar allelopathy. The objective of this study was to investigate the effects of para-hydroxybenzoic acid on photosynthesis of $P$. × euramericana "Neva". Our results could provide important information on the influence of allelochemicals on poplar cultivation.

measuring light-response parameters via the portable photosynthesis system, 15 PAR $[2,000 ; 1,800 ; 1,600$; 1,$400 ; 1,200 ; 1,000 ; 800,600,400,200,150,100,60,30$, and $0 \mu \mathrm{mol}$ (photon) $\mathrm{m}^{-2} \mathrm{~s}^{-1}$ ] were supplied by a cold lightemitting diode [LED; range 0-2,000 $\mu \mathrm{mol}$ (photon) $\mathrm{m}^{-2} \mathrm{~s}^{-1}$; peak emission wavelength of red light (90\%): 620-630 nm, and white light (10\%): 425-625 nm]. Each PAR was measured for $120 \mathrm{~s}$ and was repeated three times. The portable photosynthesis system automatically recorded PAR, net photosynthetic rate $\left(P_{\mathrm{N}}\right)$, transpiration rate $(E)$, stomatal conductance $\left(g_{\mathrm{s}}\right)$, intercellular $\mathrm{CO}_{2}$ concentration $\left(C_{\mathrm{i}}\right)$, and air $\mathrm{CO}_{2}$ concentration $\left(C_{\mathrm{a}}\right)$. The water-use efficiency (WUE) was calculated as WUE $=P_{\mathrm{N}} / E$ and the stomatal limitation $\left(\mathrm{L}_{\mathrm{s}}\right)$ was calculated as $\mathrm{L}_{\mathrm{s}}=1-C_{\mathrm{i}} / C_{\mathrm{a}}$ (Berry and Downton 1982, Nijs et al. 1997).

Chl fluorescence parameters: A portable pulse amplitude-modulated chlorophyll FMS-2 fluorometer (Hansatech, King's Lynn, UK) was used to measure Chl fluorescence parameters, including minimum Chl fluorescence yield of the dark-adapted state $\left(\mathrm{F}_{0}\right)$, maximal fluorescence yield of the dark-adapted state $\left(\mathrm{F}_{\mathrm{m}}\right)$, steadystate fluorescence yield $\left(\mathrm{F}_{\mathrm{s}}\right)$, minimum fluorescence of the light-adapted state $\left(\mathrm{F}_{0}{ }^{\prime}\right)$, and maximal fluorescence yield of the light-adapted state $\left(\mathrm{F}_{\mathrm{m}}{ }^{\prime}\right)$. All measurements were done on 3-4 leaves from the middle of a plant. Additional Chl fluorescence parameters were calculated according to the following equations. Maximal quantum yield of PSII photochemistry $\left(\mathrm{F}_{\mathrm{v}} / \mathrm{F}_{\mathrm{m}}\right)=\left(\mathrm{F}_{\mathrm{m}}-\mathrm{F}_{0}\right) / \mathrm{F}_{\mathrm{m}}$; photochemical quenching coefficient $\left(\mathrm{q}_{\mathrm{P}}\right)=\left(\mathrm{F}_{\mathrm{m}}{ }^{\prime}-\mathrm{F}_{\mathrm{s}}\right) /\left(\mathrm{F}_{\mathrm{m}}{ }^{\prime}-\mathrm{F}_{0}{ }^{\prime}\right)$; nonphotochemical quenching $(\mathrm{NPQ})=\left(\mathrm{F}_{\mathrm{m}}-\mathrm{F}_{\mathrm{m}}{ }^{\prime}\right) / \mathrm{F}_{\mathrm{m}}{ }^{\prime}$; and effective quantum yield of PSII photochemistry $\left(\Phi_{\mathrm{PSII}}\right)=$ $\left(\mathrm{F}_{\mathrm{m}}{ }^{\prime}-\mathrm{F}_{\mathrm{s}}\right) / \mathrm{F}_{\mathrm{m}}{ }^{\prime}$ (Krause et al. 1991, Nijs et al. 1997, Xu 2002, Zhu et al. 2011).

Response curves $\left(P_{\mathrm{N}}-\mathrm{PAR}\right)$ of $\boldsymbol{P}_{\mathrm{N}}$ to light intensity: Current research has shown that the rectangular hyperbolic 
correction model is an accurate response curve $\left(P_{\mathrm{N}}-\mathrm{PAR}\right)$ of the net photosynthetic rate to light intensity (Ye and $\mathrm{Yu}$ 2007, Lang et al. 2011, Chen et al. 2012a, Chen et al. 2012b). SPSS v. 17.0 (IBM SPSS, Chicago, IL, USA) was used to analyze the parameters of the light-response process. The calculation formulae of the rectangular hyperbolic correction model are as follows:

$$
\begin{aligned}
& P_{\mathrm{N}}=\Phi \frac{1-\beta \text { PAR }}{1+\gamma \text { PAR }} \text { PAR }-R_{\mathrm{D}} \\
& \mathrm{LSP}=\frac{\sqrt{(\beta+\gamma) / \beta}-1}{\gamma} \\
& P_{\mathrm{N} \max }=\Phi\left(\frac{\sqrt{\beta+\gamma}-\sqrt{\beta}}{\gamma}\right)^{2}-R_{\mathrm{D}}
\end{aligned}
$$

The calculation formula of quantum yield at lightcompensation point $\left(\Phi_{c}\right)$, intrinsic quantum yield $\left(\Phi_{0}\right)$, and the absolute value of the slope of the light-response curve between PAR $=0$ and PAR $=I_{c}\left(\Phi_{0}\right)$ are as follows:

$$
\Phi_{\mathrm{c}}=P_{\mathrm{N}}^{\prime}(\mathrm{PAR}=\mathrm{Ic})=\alpha \frac{1+(\gamma-\beta) \mathrm{I}_{\mathrm{c}}-\beta \gamma \mathrm{Ic}^{2}}{\left(1+\gamma \mathrm{I}_{\mathrm{c}}\right)^{2}}
$$

$\Phi_{0}=P_{\mathrm{N}}^{\prime}(\mathrm{PAR}=0)=\Phi$

$\Phi_{\mathrm{c} 0}=\left|R_{\mathrm{D}} / \mathrm{I}_{\mathrm{c}}\right|$

where $\Phi$ is the apparent quantum yield (AQY; mol mol${ }^{-1}$ ); PAR is the photosynthetic active radiation intensity [ $\mu$ mol(photon) $\mathrm{m}^{-2} \mathrm{~s}^{-1}$ ]; LSP is the light-saturation point $\left(\mu \mathrm{mol} \mathrm{m} \mathrm{m}^{-2} \mathrm{~s}^{-1}\right) ; R_{\mathrm{D}}$ is the respiration rate $\left(\mu \mathrm{mol} \mathrm{m} \mathrm{m}^{-2} \mathrm{~s}^{-1}\right)$; $\beta$ and $\gamma$ are the model coefficients; $P_{\mathrm{N}}$ is the net photosynthetic rate $\left(\mu \mathrm{mol} \mathrm{m} \mathrm{m}^{-2} \mathrm{~s}^{-1}\right) ; P_{\mathrm{Nmax}}$ is the maximum net photosynthetic rate $\left(\mu \mathrm{mol} \mathrm{m} \mathrm{m}^{-2} \mathrm{~s}^{-1}\right)$; and $I_{\mathrm{c}}$ is the lightcompensation point (LCP; $\mu \mathrm{mol} \mathrm{m} \mathrm{m}^{-2} \mathrm{~s}^{-1}$ ).

Data processing: SPSS and the Excel were used to perform one-way analysis of variance (ANOVA), using the least significant difference method (LSD). The results of different treatments were examined at the 5\% level. The response characteristics of photosynthetic parameters of poplar to different $\mathrm{p}$-HB concentrations were based on the leaf gas-exchange data obtained under the fixed light intensity.

\section{Results}

Light-response parameters: With increasing p-HB concentration, LCP and $R_{\mathrm{D}}$ clearly increased, while $P_{\mathrm{Nmax}}$, LSP, and AQY declined markedly (Fig. 1, Table 1).

Gas-exchange parameters: The photosynthetic para- meters of poplar leaves in response to $\mathrm{p}-\mathrm{HB}$ concentrations under the fixed PAR $\left[1,200 \mu\right.$ mol(photon) $\left.\mathrm{m}^{-2} \mathrm{~s}^{-1}\right]$ are shown in Table 2. At different concentrations of p-HB and under a fixed light intensity, $P_{\mathrm{N}}, E, g_{\mathrm{s}}, C_{\mathrm{i}}, \mathrm{L}_{\mathrm{s}}$, and WUE changed significantly, while with concentration of $\mathrm{p}-\mathrm{HB}$,

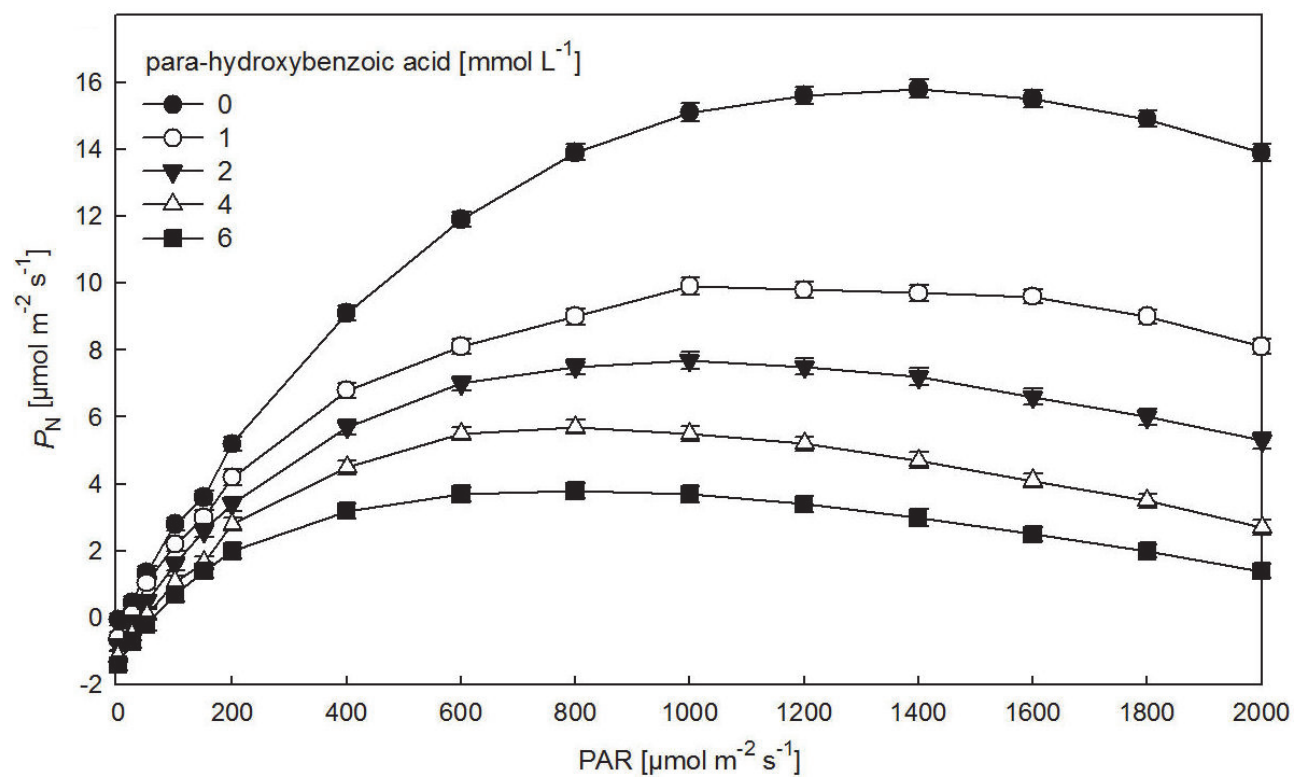

Fig. 1. Photosynthetic rate-light response curves and stimulation of Populus $\times$ euramericana "Neva" under different phenol concentrations. Values are expressed as the mean of three replicates \pm SD. $P_{\mathrm{N}}$ - net photosynthetic rate; PAR - photosynthetically active radiation. 
Table 1. Responses of apparent quantum yield (AQY), light-saturation point (LSP), light-compensation point (LCP), light-saturated net photosynthetic rate $\left(P_{\mathrm{Nmax}}\right)$, and respiration rate $\left(R_{\mathrm{D}}\right)$ of Populus $\times$ euramericana "Neva" to different para-hydroxybenzoic acid concentrations. $R^{2}$ - coefficient of determination; $\Phi_{0}$ - intrinsic quantum yield; $\Phi_{c}$ - quantum yield at light-compensation point; $\Phi_{\mathrm{c} 0}-$ absolute value of slope of light-reponse curve between PAR $=0$ and PAR $=I_{c}$.

\begin{tabular}{lllllrrrr}
\hline $\begin{array}{l}\text { Para-hydroxybenzoic acid } \\
\text { concentration [mmol L }\end{array}$ [ $\Phi_{0}$ & & $\Phi_{\mathrm{c}}$ & \multicolumn{1}{l}{$\Phi_{\mathrm{c} 0}$} & LSP & $P_{\text {Nmax }}$ & LCP & $R_{\mathrm{D}}$ & $R^{2}$ \\
\hline 0 & 0.0146 & 0.0138 & 0.0135 & 1356 & 15.83 & 5.86 & 0.178 & 0.9998 \\
1 & 0.0134 & 0.0130 & 0.0128 & 1184 & 9.82 & 16.74 & 0.476 & 0.9990 \\
2 & 0.0128 & 0.0124 & 0.0121 & 990 & 7.68 & 29.67 & 0.805 & 0.9999 \\
4 & 0.0122 & 0.0109 & 0.0101 & 846 & 5.65 & 47.21 & 1.176 & 0.9990 \\
6 & 0.0115 & 0.0102 & 0.0099 & 754 & 3.83 & 60.03 & 1.358 & 0.9998 \\
\hline
\end{tabular}

$P_{\mathrm{N}}, E, g_{\mathrm{s}}$, and $\mathrm{L}_{\mathrm{s}}$ decreased significantly (Table 2). However, with increasing $\mathrm{p}-\mathrm{HB}$ concentration, the $C_{\mathrm{i}}$ increased significantly (Table 1), but WUE increased at first and then declined. Higher WUE values were observed at the concentrations of 0,1 , and $2 \mathrm{mmol} \mathrm{L}^{-1}$.

\section{Discussion}

With increasing world population, the pressure for economic crop and grain production is also increasing. Plant allelopathy is a main reason for the decline in economic crop and grain production and has aroused the attention of the scholars all over the world. Meanwhile, phenolic acids, allelochemicals, which promote plant growth and stress resistance and also serve as pigments and defense and signal molecules, are gradually arousing concern (Makoi and Ndakidemi 2007). In agricultural ecosystems, allelochemicals such as phenolic acids are destructive for annual crop growth and soil activity and are an important cause of continuous cropping obstacles (Rice 1984, Singh et al. 2001).

Photosynthesis is an important basis for plant growth and development (Wang et al. 2010b). Currently, as a rapid, sensitive technique with nondestructive photosynthesis probes, Chl fluorescence has been applied in research for the detection of heavy metals, toxic substances, and adversity stress effects on plant photosynthesis (Brack and Frank 1998, Su et al. 2002, Ouzounidou et al. 2008, El-Hassani et al. 2009, Wang et al. 2010a).

With the increase of $\mathrm{p}-\mathrm{HB}$ concentration, light-response parameters showed that AQY, LSP, and $P_{\text {Nmax }}$ declined markedly, while LCP and $R_{\mathrm{D}}$ increased clearly. The decline of AQY implies that the conversion efficiency of low-light energy decreased (Farquhar and Sharkey 1982, Richard 2001). Meanwhile, the decrease in $P_{\mathrm{Nmax}}$ and increase in $R_{\mathrm{D}}$ indicated a lower rate of photosynthesis and higher respiration rate. The large decline in $P_{\mathrm{Nmax}}$ after the $1 \mathrm{mmol} \mathrm{L}^{-1}$ treatment indicated that the photosynthesis of $P . \times$ euramericana "Neva" was very sensitive to $\mathrm{p}-\mathrm{HB}$ stress.

In this study, our results of photosynthetic gas
Chl fluorescence parameters: Under different concentrations of $\mathrm{p}-\mathrm{HB}$, the $\mathrm{F}_{\mathrm{v}} / \mathrm{F}_{\mathrm{m}}, \Phi_{\mathrm{PSII}}, \mathrm{q}_{\mathrm{P}}$, and NPQ of poplar leaves clearly changed (Table 3 ). As the p-HB concentration increased, the $\mathrm{F}_{\mathrm{v}} / \mathrm{F}_{\mathrm{m}}$ and $\Phi_{\mathrm{PSII}}$ decreased, while $1-\mathrm{q}_{\mathrm{P}}$ increased. NPQ increased at a lower concentration, under $2 \mathrm{mmol} \mathrm{L}{ }^{-1}$, then decreased at higher concentrations.

exchange showed that $\mathrm{p}$-HB significantly inhibited the photosynthesis of $P$. × euramericana "Neva". The higher the $\mathrm{p}$-HB concentration was the greater the inhibition effect occurred, which was mainly caused by nonstomatal factors. According to studies on plant photosynthesis, as stress factor aggravating, there was a transition from stomatal limitation to nonstomatal limitation factors, which was the main reason for the reduction in photosynthesis (Wang et al. 2010a, Qian et al. 2011). However, in this study, poplar showed a nonstomatal limitation of photosynthesis, even at a low concentration of p-HB $\left(1 \mathrm{mmol} \mathrm{L}^{-1}\right)$; compared with the control, $P_{\mathrm{N}}, E, g_{\mathrm{s}}$, LSP, and $P_{\text {Nmax }}$ decreased significantly. Therefore, a concentration range of $0-1 \mathrm{mmol} \mathrm{L}^{-1}$ was shown to be a critical threshold at which a change from stomatal to nonstomatal factors caused a reduction in photosynthesis. However, further study is needed to determine the precise critical concentration.

$P_{\mathrm{N}}$ and $E$ might be affected by other physical characteristics, such as $g_{\mathrm{s}}$ and $C_{\mathrm{i}}$. Inorganic ions could be transported to different groups of plants along with upward water transport by transpiration. At the same time, $\mathrm{CO}_{2}$ was absorbed in by stomata with $\mathrm{H}_{2} \mathrm{O}$ lost to the surrounding air. p-HB damaged stomatal function and prevented the exchange of $\mathrm{H}_{2} \mathrm{O}$ and $\mathrm{CO}_{2}$, which affected the $P_{\mathrm{N}}$ and $E$ values. Along with the rapid decrease in $E$ and $P_{\mathrm{N}}$, WUE first increased $\left(0-1 \mathrm{mmol} \mathrm{L}^{-1}\right)$ and then decreased (1-6 mmol L ${ }^{-1}$ ), implying that the decline of $P_{\mathrm{N}}$ was slighter than that of $E$ at the lower concentration of p-HB $\left(0-1 \mathrm{mmol} \mathrm{L}^{-1}\right)$. The increase of LCP and decline of LSP suggest that the light-use efficiency (under both strong and weak light) declined, which is in accordance with the results of $F_{\mathrm{v}} / \mathrm{F}_{\mathrm{m}}$ and $\Phi_{\text {PSII. }}$. 
Table 2. Response of photosynthetic parameters of Populus $\times$ euramericana "Neva" to different para-hydroxybenzoic acid concentrations under the same photosynthetically active radiation $\left[1,200 \mu \mathrm{mol}\left(\right.\right.$ photon) $\left.\mathrm{m}^{-2} \mathrm{~s}^{-1}\right]$. Values are expressed as the mean of three replicates \pm SD. Means in columns within the different concentrations of para-hydroxybenzoic acid that are followed by different letters are significantly different (LSD test, $P<0.05$ ). $P_{\mathrm{N}}-$ net photosynthetic rate; $E$ - transpiration rate; $g_{\mathrm{s}}-$ stomatal conductance; $C_{\mathrm{i}}-$ intercellular $\mathrm{CO}_{2}$ concentration; $\mathrm{L}_{\mathrm{s}}$ - stomatal limitation; WUE - water-use efficiency.

\begin{tabular}{lllllll}
\hline $\begin{array}{l}\text { Para-hydroxybenzoic } \\
\text { acid concentration } \\
{\left[\mathrm{mmol} \mathrm{L}^{-1}\right]}\end{array}$ & $\begin{array}{l}P_{\mathrm{N}} \\
{\left[\mu \mathrm{mol} \mathrm{m} \mathrm{s}^{-2}\right]}\end{array}$ & $\begin{array}{l}E \\
{\left[\mathrm{mmol} \mathrm{m}^{-2} \mathrm{~s}^{-1}\right]}\end{array}$ & $\begin{array}{l}g_{\mathrm{s}} \\
{\left[\mathrm{mmol} \mathrm{m}^{-2} \mathrm{~s}^{-1}\right]}\end{array}$ & $\begin{array}{l}C_{\mathrm{i}} \\
{\left[\mu \mathrm{mol} \mathrm{mol}^{-1}\right]}\end{array}$ & $\begin{array}{l}\mathrm{L}_{\mathrm{s}} \\
\end{array}$ & $\begin{array}{l}\text { WUE } \\
{\left[\mu \mathrm{mol} \mathrm{mmol}^{-1}\right]}\end{array}$ \\
\hline 0 & $15.60 \pm 1.07^{\mathrm{a}}$ & $4.03 \pm 0.30^{\mathrm{a}}$ & $61.13 \pm 6.29^{\mathrm{a}}$ & $236.61 \pm 6.23^{\mathrm{a}}$ & $0.35 \pm 0.02^{\mathrm{a}}$ & $3.87 \pm 0.03^{\mathrm{a}}$ \\
1 & $9.80 \pm 0.87^{\mathrm{b}}$ & $2.47 \pm 0.22^{\mathrm{b}}$ & $36.32 \pm 4.6^{\mathrm{b}}$ & $253.85 \pm 4.25^{\mathrm{ab}}$ & $0.30 \pm 0.02^{\mathrm{ab}}$ & $3.96 \pm 0.10^{\mathrm{a}}$ \\
2 & $7.50 \pm 0.79^{\mathrm{bc}}$ & $2.10 \pm 0.17^{\mathrm{bc}}$ & $27.24 \pm 3.03^{\mathrm{c}}$ & $261.04 \pm 6.12^{\mathrm{bc}}$ & $0.28 \pm 0.02^{\mathrm{bc}}$ & $3.57 \pm 0.11^{\mathrm{b}}$ \\
4 & $5.20 \pm 0.58^{\mathrm{cd}}$ & $1.59 \pm 0.15^{\mathrm{cd}}$ & $26.77 \pm 2.80^{\mathrm{c}}$ & $280.20 \pm 5.35^{\mathrm{c}}$ & $0.23 \pm 0.02^{\mathrm{c}}$ & $3.26 \pm 0.08^{\mathrm{c}}$ \\
6 & $3.40 \pm 0.40^{\mathrm{d}}$ & $1.31 \pm 0.14^{\mathrm{d}}$ & $25.18 \pm 2.42^{\mathrm{c}}$ & $320.91 \pm 9.78^{\mathrm{d}}$ & $0.12 \pm 0.01^{\mathrm{d}}$ & $2.60 \pm 0.05^{\mathrm{d}}$ \\
\hline
\end{tabular}

Table 3. Effects of phenol concentrations on chlorophyll fluorescence parameters of Populus $\times$ euramericana "Neva." Values are expressed as the mean of three replicates \pm SD. Means in columns within different concentrations of para-hydroxybenzoic acid that are followed by different letters are significantly different (LSD test, $P<0.05$ ). $\mathrm{F}_{\mathrm{v}} / \mathrm{F}_{\mathrm{m}}-$ maximal quantum yield of PSII; NPQ - nonphotochemical quenching; qP - photochemical quenching coefficient; $\Phi_{P S I I}$ - effective quantum yield of PSII photochemistry.

\begin{tabular}{lllll}
\hline $\begin{array}{l}\text { Para-hydroxybenzoic } \\
\text { acid concentration } \\
{\left[\mathrm{mmol} \mathrm{L}^{-1}\right]}\end{array}$ & $\mathrm{F}_{\mathrm{v}} / \mathrm{F}_{\mathrm{m}}$ & $1-\mathrm{qP}_{\mathrm{P}}$ & $\mathrm{NPQ}$ & ФPSII \\
\hline 0 & & & & \\
\hline & $0.824 \pm 0.025^{\mathrm{a}}$ & $0.252 \pm 0.026^{\mathrm{d}}$ & $0.863 \pm 0.062^{\mathrm{e}}$ & $0.544 \pm 0.050^{\mathrm{a}}$ \\
2 & $0.760 \pm 0.023^{\mathrm{b}}$ & $0.818 \pm 0.071^{\mathrm{c}}$ & $1.069 \pm 0.063^{\mathrm{b}}$ & $0.328 \pm 0.037^{\mathrm{b}}$ \\
4 & $0.733 \pm 0.022^{\mathrm{c}}$ & $1.020 \pm 0.059^{\mathrm{bc}}$ & $1.210 \pm 0.055^{\mathrm{a}}$ & $0.264 \pm 0.031^{\mathrm{c}}$ \\
6 & $0.672 \pm 0.018^{\mathrm{d}}$ & $1.045 \pm 0.065^{\mathrm{b}}$ & $0.954 \pm 0.061^{\mathrm{c}}$ & $0.236 \pm 0.029^{\mathrm{d}}$ \\
\hline
\end{tabular}

Chl fluorescence parameters represent the activity of antenna pigments for the transport of light to the reaction centers of PSII that shows the maximum efficiency of the absorption of light energy used in photochemical reactions by the photosynthetic apparatus, also with respect to the degree of photoinhibition (Chen et al. 2008).

Our study showed that with an increase in the p-HB concentration, $1-\mathrm{q}_{\mathrm{P}}$ increased, but $\Phi_{\mathrm{PSII}}$ and $\mathrm{F}_{\mathrm{v}} / \mathrm{F}_{\mathrm{m}}$ decreased (Table 3). The decline of $F_{\mathrm{v}} / \mathrm{F}_{\mathrm{m}}$ and $\Phi_{\text {PSII }}$ under increasing $\mathrm{p}-\mathrm{HB}$ concentration indicated that the potential activity of PSII decreased. The decrease of $\mathrm{q}_{\mathrm{P}}$ (or increase of $1-\mathrm{q}_{\mathrm{P}}$ ) also represents a decline in the activity of the PSII reaction centers (Piñol and Simón 2009, Zhu et al. 2011). The $\Phi_{\text {PSII }}$ value gives an estimation of efficiency (Baker and Rosenqvist 2004), with a decline in $\Phi_{\text {PSII }}$ representing weaker photochemical efficiency (Maxwell and Johnson 2000). The decrease in $\mathrm{F}_{\mathrm{v}} / \mathrm{F}_{\mathrm{m}}$ reflects a reduction in light-use efficiency (Baker 2008; Li et al. 2015), which is in accordance with the decline of LSP and increase of LCP observed in this study. Taken together, our results showed that $\mathrm{p}-\mathrm{HB}$ inhibited the activity and efficiency of PSII in $P$. × euramericana "Neva" leaves.

Our results indicated that p-HB could destroy the PSII reaction centers gradually, lead to higher restriction on the effective transfer of excited electrons and reduction of the actual light energy used for the photochemical reactions of PSII (Hang and Zhao 2010). However, with increasing
p-HB concentration, NPQ first increased and then decreased (Table 3). At lower concentrations of $\mathrm{p}-\mathrm{HB}$ $\left(\leq 2 \mathrm{mmol} \mathrm{L}^{-1}\right)$, NPQ increased, and at the same time, $1-\mathrm{q}_{\mathrm{P}}$ and $\Phi_{\mathrm{PSII}}$ decreased, indicating that thermal dissipation by PSII increased, which might help to alleviate the damage to PSII reaction centers (Brack et al. 1998; Liang et al. 2010; Liu et al. 2012). However, with $\mathrm{p}-\mathrm{HB}$ at higher concentrations $\left(>4 \mathrm{mmol} \mathrm{L} \mathrm{m}^{-1}\right)$, NPQ decreased, which indicated that the energy used for the heat dissipation of antenna pigments in PSII decreased $(\mathrm{Xu}$ 2002, Liang et al. 2010). $P_{\mathrm{N}}$ decreased at the same time, which indicated that the high $\mathrm{p}-\mathrm{HB}$ concentration might destroy some enzymes related to the xanthophyll cycle, particularly, violaxanthin de-epoxidase, which might lead to a decline in heat dissipation dependent on the xanthophyll cycle (Chen et al. 2008).

The responses of different plants to $\mathrm{p}$-HB have been recently studied. Wang et al. (2014) reported that after treatment of Malus hupehensis Rehd. seedlings with $0.4 \mathrm{mmol} \mathrm{L}^{-1} \mathrm{p}$-HB, the chlorophyll content, PSII center activities, and photosynthetic capacity decreased. The reduction in $P_{\mathrm{N}}$ under $\mathrm{p}$-HB stress was thought to be caused by nonstomatal restrictions. As both $P . \times$ euramericana "Neva" and M. hupehensis Rehd. belong to the xylophyta family, we expected similar effects of $\mathrm{p}-\mathrm{HB}$ in both species. 
In this study, when the para-hydroxybenzoic acid concentration reached $2 \mathrm{mmol} \mathrm{L}^{-1}, P_{\mathrm{N}}$ and $E$ decreased to 49.8 and $49.5 \%$, respectively. Therefore, in the continuous cropping of $P$. $\times$ euramericana "Neva", the parahydroxybenzoic acid concentration in soil should be lower than $2 \mathrm{mmol} \mathrm{L}^{-1}$, otherwise the physiological activity,

\section{References}

Baker N.R.: Chlorophyll fluorescence: a probe of photosynthesis in vivo. - Annu. Rev. Plant Biol. 59: 89-113, 2008.

Baker N.R., Rosenqvist E.: Applications of chlorophyII fluorescence can improve crop production strategies: an examination of future possibilities. - J. Exp. Bot. 55: 1607-1621, 2004.

Berry J.A., Downton W.J.S.: Environmental regulation of photosynthesis. - In: Govindjee (ed.): Photosynthesis, Vol.II. Pp. 265-335. Academic Press, New York 1982.

Brack W., Frank H.: Chlorophyll $a$ fluorescence: a tool for the investigation of toxic effects in the photosynthetic apparatus. Ecotox. Environ. Safe. 40: 34-41, 1998.

Chen D.J., Gao P.J, Wu X.B. et al.: [Chloroplast Ultrastructure and emission fluorescence spectrum characteristics for stems of Phyllostachys pubescens.] - Chin. Bull. Bot. 48: 635-642, 2013. [In Chinese]

Chen H.X., Chen W., Jiang C.D. et al.: [Effects of temperature and light treatment on violaxanthin de-epoxidase activity and xanthophyll cycle-dependent energy dissipation in wheat leaves.] - Chin. J. Plant. Ecol. 32: 1015-1022, 2008. [In Chinese]

Chen W.Y., Chen Z.Y., Luo F.Y. et al:: [Comparison between modified exponential model and common models of lightresponse curve.] - Chin. J. Plant. Ecol. 36: 1277-1285, 2012a. [In Chinese]

Chen Z.C., Wang R.R., Wang Z.W. et al.: [Light response of photosynthesis of Koelreuteria paniculata Laxm. under different soil water conditions.] - Sci. Soil Water Conserv. 10: 105-110, 2012b. [In Chinese]

Farquhar G.D., Sharkey T.D.: Stomatal conductance and photosynthesis. - Annu. Rev. Plant Phys. 33: 317-345,1982.

$\mathrm{Fu}$ W., Li P., Wu Y.: Effects of different light intensities on chlorophyll fluorescence characteristics and yield in lettuce. Sci. Hortic.-Amsterdam 135: 45-51, 2012.

Han W.H.: [The Migration and Diffusion Models of Phenolic Pollutants in the Songhua River and Carbon Emergency Measures.] - Master Thesis. Harbin Institute of Technology, Harbin 2010. [In Chinese]

Han G., Zhao Z.: [Light response characteristics of photosynthesis of four xerophilous shrubs under different soil moistures.] - Acta Ecol. Sinica 30: 4019-4026, 2010. [In Chinese]

Krause G.H., Weis E.: Chlorophyll fluorescence and photosynthesis: the basics. - Annu. Rev. Plant Biol. 42: 313349,1991 .

Kuiters A.T., Sarink H.M.: Leaching of phenolic compounds from leaf and needle litter of several deciduous and coniferous trees. - Soil Biol. Biochem. 18: 475-480, 1986.

Lang Y., Zhang G.C., Zhang Z.K. et al.: [Light response of photosynthesis and its simulation in leaves of Prunus sibirica $L$. under different soil water conditions.] - Acta Ecol. Sinica 31: 4499-4508, 2011. [In Chinese]

Li S., Yang W., Yang T. et al.: Effects of cadmium stress on leaf chlorophyll fluorescence and photosynthesis of Elsholtzia growth, and development of the plants significantly decrease. Whether a concentration of $6 \mathrm{mmol} \mathrm{L}^{-1}$ is the limiting para-hydroxybenzoic acid concentration, which $P$. × euramericana "Neva" can tolerate in order to maintain normal photosynthetic activities, it is difficult to determine from our present results.

argyi - a cadmium accumulating plant. - Int. J. Phytoremediat. 17: 85-92, 2015.

Li S.T., Zhou J.M., Wang H.Y. et al.: [Research surveys of allelopathy in plants.] - Chin. J. Ecoagricult. 10: 68-70, 2002. [In Chinese]

Liang F., Zheng C.S., Shun X.Z., Wang W.L.: [Effects of low temperature- and weak light stress and its recovery on the photosynthesis and chlorophyll fluorescence parameters of cut flower chrysanthemum.] - Chin. J. Appl. Ecol. 21: 29-35, 2010. [In Chinese]

Liu C.Y., Chen D.Y., Gai S.P. et al.: [Effects of high- and low temperature stress on the leaf PSII functions and physiological characteristics of tree peony (Paeonia suffruticosa cv. 'Roufurong').] - Chin. J. Appl. Ecol. 23: 133-139, 2012. [In Chinese]

Massacci A., Nabiev S.M., Pietrosanti L. et al.: Response of the photosynthetic apparatus of cotton (Gossypium hirsutum) to the onset of drought stress under field conditions studied by gasexchange analysis and chlorophyll fluorescence imaging. Plant Physiol. Bioch. 46: 189-195,2008.

Makoi J., Ndakidemi P.A.: Biological, ecological and agronomic significance of plant phenolic compounds in rhizosphere of the symbiotic legumes. - Afr. J. Biotechnol. 6: 1358-1368, 2007.

Maxwell K., Johnson G.N.: Chlorophyll fluorescence - a practical guide. - J. Exp. Bot. 51: 659-668, 2000.

Nijs I., Ferris R., Blum H. et al.: Stomatal regulation in a changing climate: A field study using free air temperature increase (FATI) and free air $\mathrm{CO}_{2}$ enrichment (FACE). - Plant Cell Environ. 20: 1041-1050, 1997.

Ouzounidou G., Asfi M., Sortirakis N. et al.: Olive mill wastewater triggered changes in physiology and nutritional quality of tomato (Lycopersicon esculentum Mill.) depending on growth substrate. - J. Hazard. Mater. 158: 523-530, 2008.

Patrick Z.A.: Phytotoxic substances associated with the decomposition in soil of plant residues. - Soil Sci. 111: 13-18, 1971.

Piñol R., Simón E.: Effect of 24-epibrassinolide on chlorophyll fluorescence and photosynthetic $\mathrm{CO}_{2}$ assimilation in Vicia faba plants treated with the photosynthesis-inhibiting herbicide terbutryn. - J. Plant Growth Regul. 28: 97-105,2009.

Qian Y.Q., Zhou X.X., Han L. et al.: [Rapid light-response curves of PSII chlorophyll fluorescence parameters in leaves of Salix leucopithecia subjected to cadmium-ion stress.] - Acta Ecol. Sinica 31: 6134-6142, 2011. [In Chinese]

Rice E.L.: Allelopathy. Pp. 353. Academic Press, New York 1974.

Singh H.P., Batish D.R., Kohli R.K.: Allelopathy in agroecosystems: an overview. - J. Crop Prod. 4: 1-41,2001.

$\mathrm{Su}$ X., Hu D.Q., Lin Z.F. et al.: [Effect of air pollution on the chlorophyll fluorescence characters of two afforestation plants in Guang Zhou.] - Chin. J. Plant. Ecol. 26: 599-604, 2002. [In Chinese]

Sun H.J., Sun L.Q., Wang Q. et al.: [Effects of benzoic acid and 
cinnamic acid on radicle growth, microstructure and ultrastructure of watermelon.] - Acta Agric. Boreali-Sinica 21: 77-80, 2006. [In Chinese]

Tan X.M., Wang H.T., Kong L.G. et al.: [Accumulation of phenolic acids in soil of a continuous cropping Poplar plantation and their effects on soil microbes.] - J. Shandong Univ.-Nat. Sci. 43: 14-19, 2008. [In Chinese]

Vaughan D., Ord B.: Influence of phenolic acids on morpholigical changes in roots of Pisum sativum. - J. Sci. Food Agr. 52: 289-299, 1990.

Wang L., Yang H.Q., Fan W.G., Zhang Z.: [The effect of $\mathrm{CdCl}_{2}$ treatment on photosynthetic rate and chlorophyll $a$ fluorescence parameters in Malus hupehensis leaves.] - Sci. Agric. Sinica 43: 3176-3183, 2010a. [In Chinese]

Wang S.L, Chen L.C., Liao L.P.: [Effects of three kinds of allelochemicals on growth of chinese fir seedlings.] - Chin. J. Appl. Environ. Biol. 8: 588-591, 2002. [In Chinese]

Wang Y.M., Cai H.J., Wang J.: [The influence of intercropping of wheat and pepper on photosynthetically active radiation and soil temperature.] - Chin. Rural Water Hydrop. 1: 14-19, 2010b. [In Chinese]

Wang S.J.: Advances in Polar Research. Pp. 413-413. China Forestry Publishing House, Beijing 1995.

Weidenhamer J.D., Romeo J.T.: Allelochemicals of Polygonella myriophylla: Chemistry and soil degradation. - J. Chem. Ecol. 30: 1067-1082, 2004.

Xu D.Q.: The Efficiency of Photosynthesis. Pp. 112-121. Sci. \& Technol. Press. Shanghai 2002.

Ye Z.P., Yu Q.: [Comparison of a new model of light response of photosynthesis with traditional models.] - J. Shenyang Agr. Univ. 38: 771-775, 2007. [In Chinese]

Zhao H.Y., Lu S.F., Chao R.T.: [Studies on tissue culture and gene engineering of poplar.] - Chin. Bull. Bot. 18: 169-176, 2001. [In Chinese]

Zhu Y.H., Tu N.M., Xiao H.Q., Zhang G.: [Effect of sulfur on chlorophyll fluorescence of flue-cured tobacco at maturation stage.] - Acta Ecol. Sinica 31: 3796-3801, 2011. [In Chinese] 